\title{
Targeting EGFR and HER-2 with cetuximab- and trastuzumab- mediated immunotherapy in oesophageal squamous cell
}

\section{carcinoma}

\author{
Y Kawaguchi', K Kono*,', K Mimura', F Mitsui', H Sugai', H Akaike' and H Fujii' \\ 'First Department of Surgery, University of Yamanashi, II I 0 Shimokato, Chuo-city, Yamanashi 409-3898, Japan
}

We previously reported that oesophageal squamous cell carcinoma (SCC) had a relatively high incidence of EGFR and HER-2 overexpression. Thus, anti-HER family targeting may become a promising approach to treat oesophageal SCC. In the present study, we investigated (a) the distribution of EGFR and HER-2 expression in oesophageal SCC $(n=66)$ detected by immunohistochemistry and (b) cetuximab- and/or trastuzumab-mediated biological activity (antiproliferative effect by the MTT assay, apoptosis-inducing activity by the annexin V/propidium iodide assay, and antibody-dependent cellular cytotoxicity (ADCC) by the ${ }^{51} \mathrm{Cr}$-release assay) against oesophageal SCC cell lines with various levels of EGFR and HER-2. Twelve of the 66 patients (I 8\%) showed both EGFR- and HER-2 expression. Out of both EGFR- and HER-2-positive cases, nine cases (75\%) showed EGFR and HER-2 expression in individually distinct regions. Furthermore, the combination of cetuximab and trastuzumab could induce synergistic antiproliferative effects and additional ADCC activities against not all, but several oesophageal SCC cell lines with EGFR and HER-2 expression. The combination of cetuximab and trastuzumab may be useful in the treatment of oesophageal SCC with EGFR and HER-2 expression. British Journal of Cancer (2007) 97, 494-50I. doi:I0.I038/sj.bjc.6603885 www.bjcancer.com

Published online 10 July 2007

(c) 2007 Cancer Research UK

Keywords: cetuximab; trastuzumab; EGFR; HER-2; oesophageal cancer

Oesophageal cancer is the sixth most frequent cause of cancer death worldwide (Pisani et al, 1993). Most patients with oesophageal cancer in Japan have squamous cell carcinoma (SCC), while most of those in Western countries have adenocarcinoma. Despite improvements in surgical techniques and perioperative management (Akiyama et al, 1994; Ando et al, 2000), and surgery combined with chemotherapy (Ando et al, 2003) and/or radiotherapy (Ishikura et al, 2003), the prognosis remains poor. Therefore, for oesophageal SCC patients, novel therapies such as molecular-targeted therapy, including small molecule inhibitors of tyrosine kinases or humanised monoclonal antibodies, are very much needed.

The HER family of receptor tyrosine kinases consists of four members: EGFR (HER-1), HER-2, HER-3, and HER-4. The HER family-related signalling is reported to play an important role in modulating cell proliferation, survival, migration, and differentiation. Despite the large number of ligands so far identified for EGFR and HER-3 and -4 , no direct ligand for HER-2 has yet been discovered. As HER-2 is the preferred heterodimerisation partner for all other HER family members, increasing evidence suggests that the primary function of HER-2 is as a co-receptor (Tzahar et al, 1996; Graus-Porta et al, 1997). For example, when ligands such as EGF bind to EGFR, EGFR is heterodimerised with HER-2, leading to the subsequent activation of EGFR tyrosine kinase.

*Correspondence: Dr K Kono; E-mail: kojikono@yamanashi.ac.jp Revised 16 April 2007; accepted 20 June 2007; published online 10 July 2007
Overexpression of the HER family members has been identified in a variety of human cancers such as gastrointestinal tract (Ghaderi et al, 2002; Kimura et al, 2004), colorectal (Hayashi et al, 1994; Porebska et al, 2000; Ooi et al, 2004), breast (Suo et al, 2002; Witton et al, 2003; Abd El-Rehim et al, 2004; DiGiovanna et al, 2005), lung (Hirsch et al, 2003), prostate (Di Lorenzo et al, 2002), and bladder cancers (Chow et al, 2001; Wester et al, 2002), and is correlated in a wide variety of tumours with the progression (Yarden and Sliwkowski, 2001). In particular, we and others have recently reported that the overexpression of EGFR of oesophageal SCC, partially accounted for by gene amplification, is found in 50-70\% (Itakura et al, 1994; Hanawa et al, 2006), and is indicative of a poor prognosis (Ozawa et al, 1989; Yano et al, 1991). Moreover, we showed that the overexpression of HER-2 in oesophageal SCC was found in 30.3\% (Mimura et al, 2005b). These results indicated that oesophageal SCC shows a relatively high incidence of EGFR and/or HER-2 overexpression.

There are several potential strategies for anti-HER family targeting. Two anti-HER family-targeting therapies that have been in clinical development are small-molecule EGFR tyrosine kinase inhibitors such as gefitinib (Ranson et al, 2002; Fukuoka et al, 2003) and humanised antibodies against the HER family represented by cetuximab and trastuzumab (Herbst and Hong, 2002; Needle, 2002). There are many mechanisms that are thought to contribute to the antitumour activity of cetuximab and trastuzumab, including a direct inhibition of EGFR tyrosine kinase activity (Sato et al, 1983; Sliwkowski et al, 1999), the inhibition of cell cycle progression (Wu et al, 1995; Peng et al, 1996), and increased levels 
and activities of pro-apoptotic molecules (Wu et al, 1995; Cuello et al, 2001; Liu et al, 2001). We recently reported the application of trastuzumab for oesophageal SCC with the analysis of antibodydependent cellular cytotoxicity (ADCC) mediated by trastuzumab (Mimura et al, 2005a). These results encourage us to apply a combination therapy of cetuximab and trastuzumab for oesophageal SCC, aiming at a synergistic effect. Thus, it is important to identify how expressions of EGFR and HER-2 are distributed in oesophageal SCC and if the combination of cetuximab and trastuzumab has a synergistic antitumour effect against oesophageal SCC.

In the present study, we investigated (a) the distribution of EGFR and HER-2 expression in oesophageal SCC detected by immunohistochemistry (IHC) and (b) the biological activity (antiproliferative effect, apoptosis-inducing activity, and ADCC) of cetuximab and trastuzumab against oesophageal SCC cell lines with various levels of EGFR and HER-2.

\section{MATERIALS AND METHODS}

\section{Patients}

We examined 66 cases of primary oesophageal SCCs that were histologically diagnosed and treated in the First Department of Surgery, University of Yamanashi Hospital. The patients had not received irradiation or chemotherapy before surgery. All patients had undergone oesophagectomy with two-field $(n=39)$ or threefield $(n=27)$ lymph node dissection between 1994 and 1999. The patients were classified using the tumour node metastasis (TNM) classification. The characteristics of the patients are shown in Table 1 . The study was approved by the Ethical Committee of the University of Yamanashi, and written informed consent was obtained from all individuals.

Table I Clinical features of the patients $(n=66)$

\begin{tabular}{lr}
\hline Age (years) & \\
Mean & 65.3 \\
Range & $45-8$ \\
Gender & \\
Male & 62 \\
Female & 4 \\
& \\
Primary tumour ${ }^{\mathrm{a}}$ & \\
PTis & 2 \\
PTIa & 8 \\
PTIb & 19 \\
PT2 & 5 \\
PT3 & 32 \\
& \\
Lymph node metastasis & \\
Negative & 29 \\
Positive & 37 \\
Histological grade & \\
Well differentiated & 16 \\
Moderately differentiated & 35 \\
Poorly differentiated & 15 \\
& \\
Stage & \\
O & \\
I & \\
II & \\
III & 5 \\
IVa & 26 \\
IVb & 19 \\
\hline
\end{tabular}

${ }^{a}$ The grade of tumour and stages were defined according to the UICC (TNM) classification.

\section{Cell lines and fresh tumour samples}

Oesophageal SCC cell lines TE3, TE4, and TE5 were a kind gift from Dr Nishihara (Institute of Development, Aging and Cancer, University of Tohoku, Sendai, Japan). The oesophageal SCC cell line KYSE50 was purchased from the Health Science Research Resources Bank (Osaka, Japan). All cells were cultured in RPMI 1640 medium with $5 \%$ fetal bovine serum, 100 units $\mathrm{ml}^{-1}$ penicillin, $100 \mu \mathrm{g} \mathrm{ml}^{-1}$ streptomycin, and $2 \mathrm{mmoll}^{-1}$ L-glutamine.

Primary solid tumour from oesophageal SCC patients $(n=6)$ was isolated during surgery and was homogenised by mechanical mincing. Then, cell mixtures were passed through a cell strainer (Becton Dickinson Labware, Franklin Lakes, NJ, USA) and suspended as a single-cell suspension. A single-cell suspension derived from solid tumours and malignant pleural effusion was purified by centrifugation with Ficoll - Paque (Pharmacia, Uppsala, Sweden).

\section{Chemicals and antibodies}

Humanised mouse anti-human EGFR antibody, cetuximab $\left(\right.$ Erbitux $\left.^{\mathrm{TM}}\right)$, was purchased from Merck (Dietikon, Switzerland). The anti-HER-2 monoclonal antibody trastuzumab (Herceptin ${ }^{\mathrm{TM}}$ ) and anti-CD20 mAb rituxan, which is an isotype-matched control $\mathrm{mAb}$, were purchased from Roche (Basel, Switzerland).

\section{Immunohistochemistry}

All resected oesophageal samples were immediately immersed in $20 \%$ buffered neutral formalin, fixed overnight, and embedded in paraffin according to standard procedures.

To detect EGFR, a paraffin-embedded tissue specimen was sectioned at $4 \mu \mathrm{m}$ thickness and immunohistochemically stained by the labelled streptavidin biotin (LSAB) method. After deparaffinisation and rehydration, the sections were autoclaved in $0.01 \mathrm{M}$ citrate buffer $(\mathrm{pH} 7.0)$ at $121^{\circ} \mathrm{C}$ for $10 \mathrm{~min}$. Then, the sections were cooled at room temperature for $60 \mathrm{~min}$, immersed in 3\% hydrogen peroxidase for $10 \mathrm{~min}$ to block endogenous peroxidase activity, and then washed in phosphate-buffered saline (PBS) for 5 min. To detect EGFR, mouse anti-human EGFR mAb (DakoCytomation, Glostrup, Denmark) was used. The sections were incubated with the antibody (diluted $1: 40$ ) for $24 \mathrm{~h}$ at $4^{\circ} \mathrm{C}$ in a moist chamber. After washing three times with PBS for $5 \mathrm{~min}$, the sections were reacted with the secondary antibody (biotinylated anti-mouse antibody) for $30 \mathrm{~min}$ at room temperature. Then the sections were washed again three times with PBS for 5 min after which they were reacted with peroxidase-conjugated streptavidin for $30 \mathrm{~min}$ at room temperature. After this, the sections were washed again three times with PBS for $5 \mathrm{~min}$ and were reacted with a solution containing $0.06 \mathrm{~mm} 3,3^{\prime}$-diaminobenzidine and $2 \mathrm{~mm}$ hydrogen peroxide in $0.05 \%$ Tris $-\mathrm{HCl}$ buffered at $\mathrm{pH} 7.6$ for $10 \mathrm{~min}$. They were then counterstained with haematoxylin for $30 \mathrm{~s}$. After dehydrating with 60-100\% isopropyl alcohol, penetrating, and mounting, the sections were observed.

To detect HER-2, immunohistochemical staining was performed using the HercepTest (DakoCytomation) according to the recommendations of the manufacturer. Deparaffinised and rehydrated tissue sections were incubated with the Epitope Retrieval Solution in a hot water bath for $40 \mathrm{~min}$ at $95-99^{\circ} \mathrm{C}$. Then, the sections were cooled to room temperature for $20 \mathrm{~min}$, washed with Tris buffer for $5 \mathrm{~min}$, and endogenous peroxidase was blocked with $3 \%$ hydrogen peroxide for $5 \mathrm{~min}$. The primary antibody was rabbit polyclonal antibody to human HER-2, which recognises an intracytoplasmic part of HER-2, and the primary negative control antibody was an immunoglobulin fraction of normal rabbit serum at an equivalent protein concentration to the antibody to HER-2. The sections were washed with TRIS buffer for $5 \mathrm{~min}$ and incubated with the primary antibody or the primary negative 
control antibody at room temperature for $30 \mathrm{~min}$. After rewashing with Tris buffer for $5 \mathrm{~min}$ twice, the primary antibody was detected by incubating at room temperature for $30 \mathrm{~min}$ using the visualisation reagents, dextran polymer conjugated with horseradish peroxidase and affinity-isolated goat anti-rabbit immunoglobulin. Subsequently, following the rewashing with Tris buffer for $5 \mathrm{~min}$ twice, diaminobenzidine was added as a visualisation reagent for $10 \mathrm{~min}$ and sections were counterstained with haematoxylin.

EGFR or HER-2 positivity in the IHC analysis was carried out by three observers (YK, FM, and KK). The intensity of reactivity was scored using four categories: negative, no discernible staining or background type staining; $1+$, definite cytoplasmic staining and/ or equivocal discontinuous membrane staining; $2+$, unequivocal membrane staining with moderate intensity; and $3+$, strong and complete plasma membrane staining.

\section{Flow cytometry}

For the analysis of EGFR expression by flow cytometry, mouse anti-human EGFR mAb (DakoCytomation) as the primary $\mathrm{mAb}$ and an FITC-conjugated polyclonal rabbit anti-mouse $m A b$ as the secondary $\mathrm{mAb}$ (DakoCytomation) were used, and for the analysis of HER-2 expression, a phycoerythrin-labelled anti-HER-2/neu mAb (Becton Dickinson, San Jose, CA, USA) was used. As a negative control for the primary $\mathrm{mAb}$, mouse immunoglobulin G1 mAb (Beckman-Coulter, Miami, FL, USA) was used.

Each step of the incubation with $\mathrm{mAb}$ was performed at $4{ }^{\circ} \mathrm{C}$ for $30 \mathrm{~min}$. After cells were washed twice in PBS, the stained cells were analysed on a flow cytometer.

\section{Fluorescence in situ hybridisation analysis}

Fluorescence in situ hybridisation (FISH) analysis was carried out using the PathVysion HER-2 DNA Probe Kit (Vysis, Downers Grove, IL, USA). The HER-2/neu-SpectrumOrange probe contains a DNA sequence specific for the HER-2 gene locus (17q11.2-q12). The chromosome enumeration probe 17 (CEP 17)/SpectrumGreen probe contains alpha-satellite DNA that hybridises to the D17Z1 locus (centromere region of chromosome 17). To determine the copy number for chromosome 17, we used CEP 17 as the control. Fluorescence in situ hybridisation procedures were conducted according to the guidelines of the manufacturer, except the removal of the protein from the tissue sections as described previously (Takehana et al, 2002). In brief, deparaffinised and dehydrated sections were incubated in $20 \%$ sodium bisulphate $/ 2 \times$ standard saline citrate (SSC) at $43^{\circ} \mathrm{C}$ for $20 \mathrm{~min}$. After being washed with SSC, sections were treated with proteinase $\mathrm{K}$ (Boehringer-Mannheim, Mannheim, Germany) at $37^{\circ} \mathrm{C}$ for $25 \mathrm{~min}$. Subsequently, denaturation, hybridisation, and post-hybridisation washing were carried out according to the manufacturer's protocol, and the sections were counterstained with $4^{\prime}, 6$-diamidine-2'-phenylindole dihydrochloride (Oncor, Gaithersburg, MD, USA). Fluorescence in situ hybridisation analysis was performed using a fluorescence microscope (Olympus, Tokyo, Japan) equipped with Triple Bandpass Filter sets (Vysis). Signals were countered for at least 40 cancer nuclei per tumour. In accordance with our previous studies with FISH, a cell was considered to show amplification when a definite cluster or more than 10 orange signals of HER-2 were observed (Takehana et al, 2002).

\section{Antibody-dependent cell-mediated cytotoxicity assay}

Peripheral blood mononuclear cells (PBMC) were separated from peripheral blood obtained from healthy donors and oesophageal SCC patients before treatment by centrifugation with Ficoll-Paque (Pharmacia). After the target cells were labelled with $50 \mu \mathrm{Ci}$ of ${ }^{51} \mathrm{Cr}$ for $60 \mathrm{~min}$, target cells $\left(5 \times 10^{3}\right.$ well $\left.^{-1}\right)$ and PBMC from healthy donors or oesophageal cancer patients as effector cells were co-incubated at various effector/target ratios in $200 \mu \mathrm{l}$ of X-VIVO medium in a 96-well U-bottomed plate in triplicate with indicated doses of cetuximab or/and trastuzumab or a control antibody, rituxan. After $6 \mathrm{~h}$ of incubation, the radioactivity of the supernatant $(100 \mu \mathrm{l})$ was measured with a $\gamma$-counter. The percentage of specific lysis $=100 \times($ experimental c.p.m. - spontaneous c.p.m. $) /$ (maximum c.p.m.- spontaneous c.p.m.).

\section{Apoptosis}

Each cell line $\left(2 \times 10^{5}\right.$ cells $)$ was incubated in $2 \mathrm{ml}$ of X-VIVO with control $\mathrm{mAb}$ alone, cetuximab $\left(0.5 \mu \mathrm{g} \mathrm{ml}^{-1}\right)$ alone, trastuzumab $\left(10 \mu \mathrm{g} \mathrm{ml}^{-1}\right)$ alone, and cetuximab in combination with trastuzumab at $37^{\circ} \mathrm{C}$ in a six-well plate. After incubation for $24 \mathrm{~h}$, apoptosis in each cell line was measured by staining with FITC-conjugated annexin- $\mathrm{V}$ and propidium iodide (PI) using a MEBCYTO Apoptosis kit (MBL, Nagoya, Japan) following the manufacturer's recommendations.

\section{MTT cell proliferation assay}

Each cell line ( 2500 cells) was incubated in $200 \mu$ l of X-VIVO with indicated doses of cetuximab or/and trastuzumab, or a control antibody in a 96-well flat-bottomed plate in triplicate. After incubation for $96 \mathrm{~h}$ at $37^{\circ} \mathrm{C}, 50 \mu \mathrm{l}$ of MTT (3-(4,5-dimethylthiazol2-yl)-2,5-diphenyltetrazolium bromide, $2 \mathrm{mg} \mathrm{ml}^{-1}$; Sigma, St Louis, MO, USA) was added to each well and incubation was carried out for $4 \mathrm{~h}$. Then, the supernatant was discarded and the crystal products were eluted with DMSO (50 $\mu \mathrm{lwell}^{-1}$; Sigma). Colorimetric evaluation was performed using a spectrophotometer at $570 \mathrm{~nm}$. The inhibition of proliferation was shown as \% cell growth inhibition induced by cetuximab or/and trastuzumab in comparison with that induced by control mAb.

\section{Survival analysis}

Actuarial overall survival rates were analysed by the Kaplan-Meier method, and survival was measured in months from operation to death or the last review. The log-rank test was applied to compare the two groups.

\section{Statistics}

To evaluate significant differences between groups, Student's $t$-test was performed. Significance was considered at $P<0.05$.

\section{RESULTS}

\section{Frequencies and patterns of EGFR and HER-2 expression in oesophageal SCC}

Sixty-six oesophageal SCC tumours were examined for both EGFR and HER-2 expression in serial sections by IHC. EGFR-positive expression was observed in 22 cases (33\%), while HER-2-positive expression was noted in 20 cases (31\%). Both EGFR and HER-2 expressions in the same patients were observed in 12 cases $(18 \%)$ (Figures 1 and 2), in which expressions of both EGFR and HER-2 were seen in the same tumour regions in two cases (Figure 1), and EGFR and HER-2 expressions were seen in individually distinct regions in nine cases (Figure 2). The data of EGFR and HER-2 expression in oesophageal SCC indicated that $45 \%$ of the patients showed either EGFR or HER-2 expression, and $18 \%$ of the patients showed both EGFR and HER-2. Of both EGFR- and HER-2-positive cases, $75 \%$ showed EGFR and HER-2 expression in individually distinct regions. 


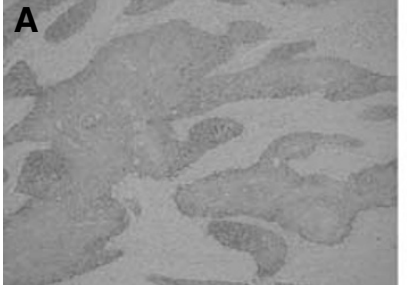

$\operatorname{EGFR}(+) \times 100$

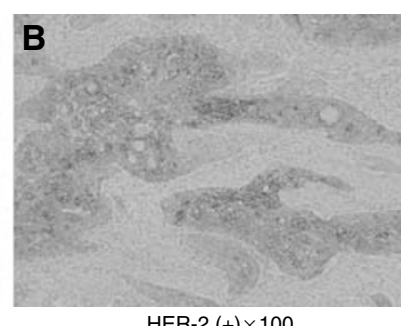

HER-2 $(+) \times 100$
Figure I Immunohistochemical staining of EGFR and HER-2 in oesophageal SCC. In oesophageal SCC, EGFR and HER-2 expressions were evaluated by $I H C$ in the serial sections. Representative stainings for EGFR $(\mathbf{A})$ and HER-2 (B) are shown, and both expressions were seen in the same regions of the oesophageal SCC tumour $(\times 100)$.
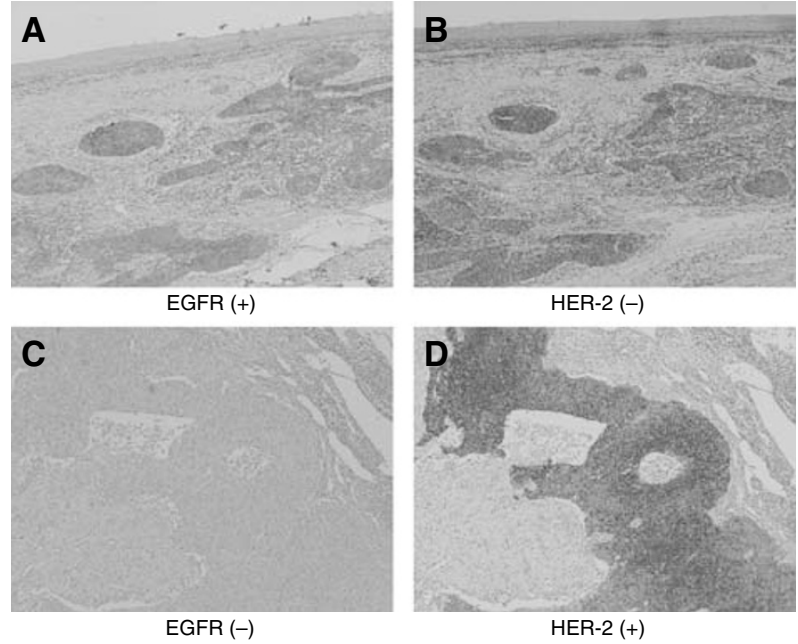

Figure 2 Immunohistochemical staining of EGFR and HER-2 in oesophageal SCC. In oesophageal SCC, EGFR and HER-2 expressions were evaluated by $I H C$ in the serial sections $(\times 100)$. The region with EGFR-positive expression (A) was negative for HER-2 (B) in the same tumour. On the contrary, the region with HER-2-positive expression (D) was negative for EGFR $(\mathbf{C})$ in the same tumour.

Furthermore, distribution of the grading of IHC for EGFR and HER-2 is shown in Table 2, indicating that there were variable patterns in their grading.

\section{Oesophageal SCC patient survival in relation to EGFR and HER-2 expression}

There was a tendency that the survival rate of patients with both EGFR $(+)$ and HER-2 $(+)$ was lower than those with EGFR $(-)$ and HER-2 (-), although it was not significant (Figure 3 ).

\section{Synergistic antiproliferative effect of cetuximab and trastuzumab against oesophageal SCC}

We have reported previously six different oesophageal SCC cell lines with variable expressions of HER-2 (Mimura et al, 2005a). Of these, TE3 was selected as a low-HER-2- and high-EGFRexpressing cell, KYSE50 and TE5 as a moderate-HER-2- and moderate-EGFR-expressing cell, and TE4 as a high-HER-2- and low-EGFR-expressing cell in the present study analysed by flow cytometry (Table 3 ). In FISH analysis, HER-2 gene amplification was seen in TE4 (Table 3), and polysomy, in which cancer nuclei showed more than three HER-2 signals accompanied with the same
Table 2 Grading patterns of HER-2 and EGFR expression in oesophageal SCC $(n=66)$

\begin{tabular}{|c|c|c|c|c|c|c|}
\hline & & \multicolumn{4}{|c|}{ IHC scores of HER-2 } & \multirow[b]{2}{*}{ Total } \\
\hline & & $3+$ & $2+$ & I+ & 0 & \\
\hline \multirow[t]{5}{*}{$\mathrm{IHC}$ scores of EGFR } & $3+$ & 2 & 3 & I & 5 & 11 \\
\hline & $2+$ & 0 & 0 & 4 & 4 & 8 \\
\hline & $1+$ & I & 0 & I & I & 3 \\
\hline & 0 & 0 & 3 & 5 & 36 & 44 \\
\hline & Total & 3 & 6 & | | & 46 & 66 \\
\hline
\end{tabular}

$\mathrm{IHC}=$ immunohistochemistry; SCC $=$ squamous cell carcinoma.

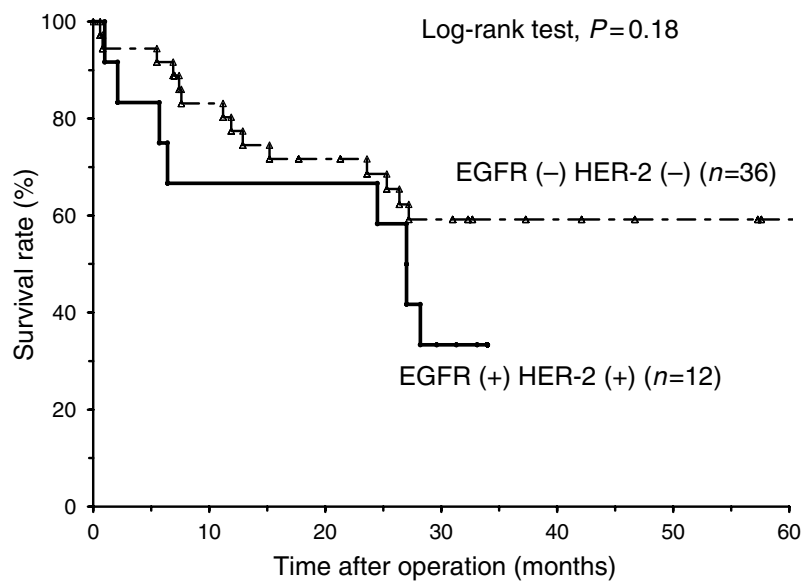

Figure 3 Survival curves of the patients with oesophageal SCC in relation to EGFR and HER-2 expression. Actuarial overall survival rates were analysed by the Kaplan-Meier method, and survival was measured in months from operation to death or the last review.

Table 3 Antitumour effect against oesophageal cancer cell lines

\begin{tabular}{|c|c|c|c|c|}
\hline & TE3 & TE5 & KYSE50 & TE4 \\
\hline \multicolumn{5}{|l|}{ EGFR and HER-2 status } \\
\hline EGFR FACS (MFI) & 211 & 150 & 114 & 76 \\
\hline HER-2 FACS (MFI) & 46 & 113 & 83 & 258 \\
\hline HER-2 FISH & Polysomy & Polysomy & Polysomy & Cluster \\
\hline \multicolumn{5}{|l|}{$\%$ Inhibition of growth (MTT) } \\
\hline $\mathrm{Ce}\left(0.5 \mu \mathrm{g} \mathrm{ml}^{-1}\right)$ & $55.1 \pm 1.1$ & $21.7 \pm 1.3$ & $33.5 \pm 3.8$ & $-3.8 \pm 5.2$ \\
\hline $\operatorname{Tra}\left(10 \mu \mathrm{g} \mathrm{ml}^{-1}\right)$ & $-2.2 \pm 5.4$ & 2.8 & $16.8 \pm$ & $9.7 \pm 3.6$ \\
\hline $\mathrm{Ce}+\mathrm{Tra}$ & $74.3 \pm 2.4$ & $32.9 \pm 2.2$ & $39.8 \pm 4.1$ & $4.1 \pm 3.1$ \\
\hline \multicolumn{5}{|l|}{ Apoptosis (\%) } \\
\hline Medium & $4.7 \pm 1.4$ & $3.2 \pm 0.6$ & $7.8 \pm 0.3$ & $8.2 \pm 0.7$ \\
\hline Medium+Ce $\left(0.5 \mu \mathrm{g} \mathrm{ml}^{-1}\right)$ & $8.7 \pm 0.6$ & $5.0 \pm 0.5$ & $9.1 \pm 0.7$ & $9.8 \pm 1$ \\
\hline Medium+Tra $\left(10 \mu \mathrm{g} \mathrm{ml}^{-1}\right)$ & $4.2 \pm 0.6$ & $2.5 \pm 0.1$ & $8.5 \pm 2.3$ & $10.0 \pm 0.7$ \\
\hline Medium+Ce+Tra & $13.7 \pm 2.3$ & $5.3 \pm 0.3$ & $11.1 \pm 0.5$ & $11.5 \pm 2.2$ \\
\hline
\end{tabular}

Cet = cetuximab; FACS = fluorescence-activated cell sorting; FISH = Fluorescence in situ hybridisation; MFI = mean fluorescence intensity; $M T T=3-(4,5-$ dimethylthiazol2-yl)-2,5-diphenyltetrazolium bromide; Tra $=$ trastuzumab.

number of centromere 17 signals, was seen in TE3, TE5, and KYSE50 (Table 3). There was no significant quantitative correlation between HER-2 and EGFR expression analysed by flow cytometry in six different oesophageal SCC cell lines (data not shown) 
Next, we examined HER-2 and EGFR expression in freshly isolated tumours (primary tumour and malignant pleural effusion) derived from six different oesophageal SCC patients. Representative flow data revealed the weak or moderate, but significant levels of HER-2 and EGFR expression in comparison with oesophageal SCC cell lines analysed by flow cytometry (Figure 4).

To examine the antiproliferative activity of cetuximab and/or trastuzumab, the MTT assay was performed. Of note, synergistic antiproliferative effects of cetuximab and trastuzumab were observed in TE3 (HER-2 low and EGFR high), while an additional antiproliferative effect was seen in KYSE50 (Table 3). Furthermore, the synergistic antiproliferative effects were confirmed in variable dose combinations of cetuximab and trastuzumab, and the same effects were also observed in the different oesophageal SCC TE5 (HER-2 moderate and EGFR - moderate; Figure 5). To examine the apoptosis-inducing activity of cetuximab and/or trastuzumab, the annexin-PI assay was performed. There were marginal levels of apoptosis induced by cetuximab and/or trastuzumab (Table 3).

\section{Cetuximab- and/or trastuzumab-mediated ADCC for oesophageal SCC}

Next, we investigated whether the combination of cetuximab and trastuzumab induces synergistic effects in ADCC against oesophageal SCC with different levels of EGFR and HER-2. Representative data with several dose combinations of cetuximab and trastuzumab induced very marginal enhancements of ADCC derived from healthy donor's PBMC against oesophageal SCC (Figure 6). Summarised data using PBMC from healthy donors $(n=5)$ and oesophageal cancer patients $(n=5)$ showed that marginal additional effects of cetuximab and trastuzumab were found only

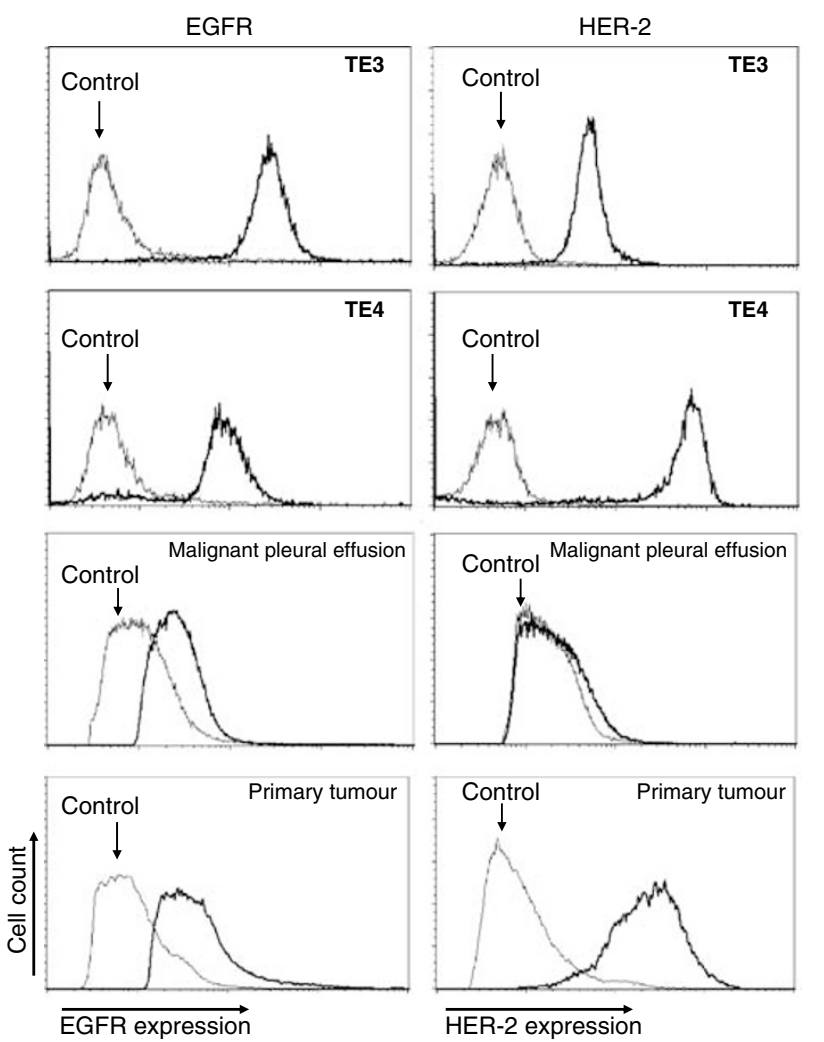

Figure 4 The degree of EGFR and HER-2 expression on oesophageal SCC cell lines and freshly isolated SCC tumours. EGFR and HER-2 expression was evaluated by flow cytometric analysis on oesophageal SCC cell lines and freshly isolated SCC tumours derived from two different patients. in ADCC for TE3, while no significant effects for KYSE50 or TE4 were seen (Figure 7).

\section{DISCUSSION}

The present study contains important findings relevant to EGFRand HER-2-targeted therapy for oesophageal SCC. First, 30 out of 66 patients $(45 \%)$ showed either EGFR or HER-2 expression, and $18 \%$ of the patients showed both EGFR and HER-2. Second, the combination of cetuximab and trastuzumab could induce synergistic antiproliferative effects against not all, but several oesophageal SCC cell lines with EGFR and HER-2 expression.

Activation of the HER family triggers a network of signalling pathways related to tumour cell proliferation and migration (Yarden and Sliwkowski, 2001). A number of strategies against EGFR and HER-2 have been developed, including mAbs and smallmolecule kinase inhibitors (Mendelsohn and Baselga, 2003). There have been data from clinical trials demonstrating the results of applying anti-EGFR tyrosine kinase inhibitors (gefitinib or erlotinib) to oesophageal adenocarcinoma (Dragovich et al, 2006; Kwak et al, 2006), indicating that erlotinib may be active in patients with oesophageal adenocarcinoma and the useful molecular marker will be needed to predict the therapeutic response.

Although there is no previous report describing the clinical application of cetuximab to oesophageal SCC patients, it has been shown that cetuximab-induced antitumour activity did not correlate directly with the levels of EGFR expression in human
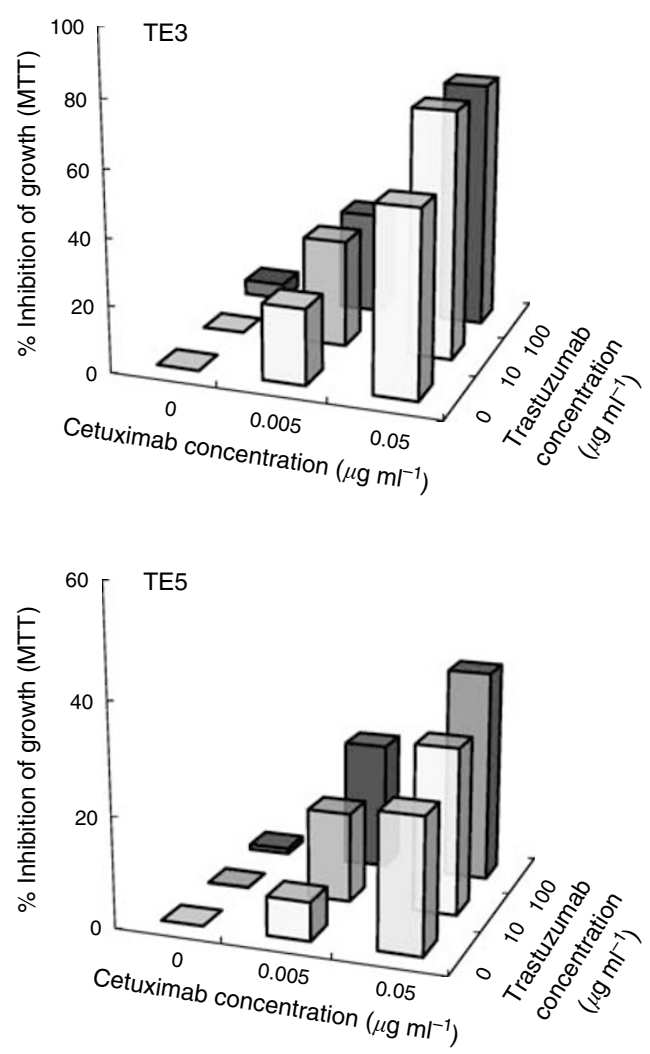

Figure 5 Synergistic antiproliferative effects of cetuximab and trastuzumab for oesophageal SCC cell lines. The oesophageal SCC lines, TE3 (HER-2 low and EGFR high) and TE5 (HER-2 moderate and EGFR moderate), were analysed by the MTT assay in various dose combinations of cetuximab and trastuzumab. The inhibition of proliferation was shown as $\%$ cell growth inhibition induced by cetuximab and/or trastuzumab in comparison with that induced by control mAb. 

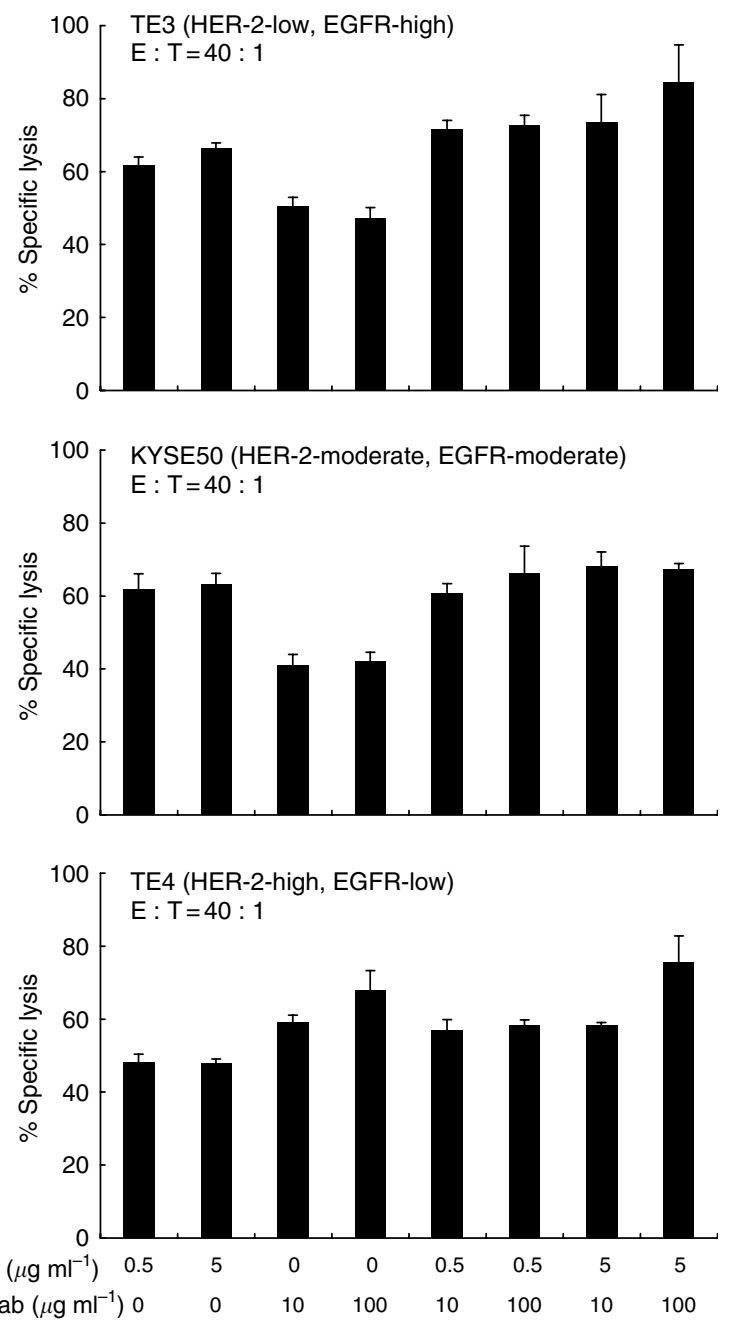

Figure 6 Cetuximab- and/or trastuzumab-mediated ADCC for oesophageal SCC cell lines. Oesophageal SCC cell lines with various levels of EGFR and HER-2 expression (TE3, KYSE50, and TE4) were analysed for ADCC derived from healthy donor's PBMC in various dose combinations of cetuximab, trastuzumab, and control mAb by the $6-h^{51} \mathrm{Cr}$ release assay. $\mathrm{E}: \mathrm{T}$, effector/target ratios.

tumour xenograft models (Wild et al, 2006). These observations suggest that molecular events other than EGFR levels are true determinants of in vivo responsiveness to EGFR-targeted therapy, and further investigation is necessary to find out the factor that affects the antitumour effect of cetuximab and gefitinib.

We recently reported that treatment with trastuzumab could induce antitumour activities against oesophageal SCC with HER-2 expression, mainly mediated by ADCC activity. However, the trastuzumab-mediated ADCC activities reflected the degree of HER-2 expression, and furthermore, patients' PBMC-derived ADCC was impaired in comparison to healthy donors. These results suggested that some modalities aiming at enhancing the trastuzumab-mediated antitumour effect are needed for the successful treatment of oesophageal SCC with trastuzumab. One possible strategy to enhance antitumour activities is a combination of trastuzumab with anti-EGFR mAb, cetuximab.

With regard to the expression of HER-2 and EGFR on oesophageal SCC, EGFR-positive tumours were observed in $35 \%$ of patients with oesophageal SCC, and HER-2-positive tumours were observed in $31 \%$ of them in the present study, in line with previous reports (Mimura et al, 2005b). This result was the high-end of the data in literature showing HER-2 expression in
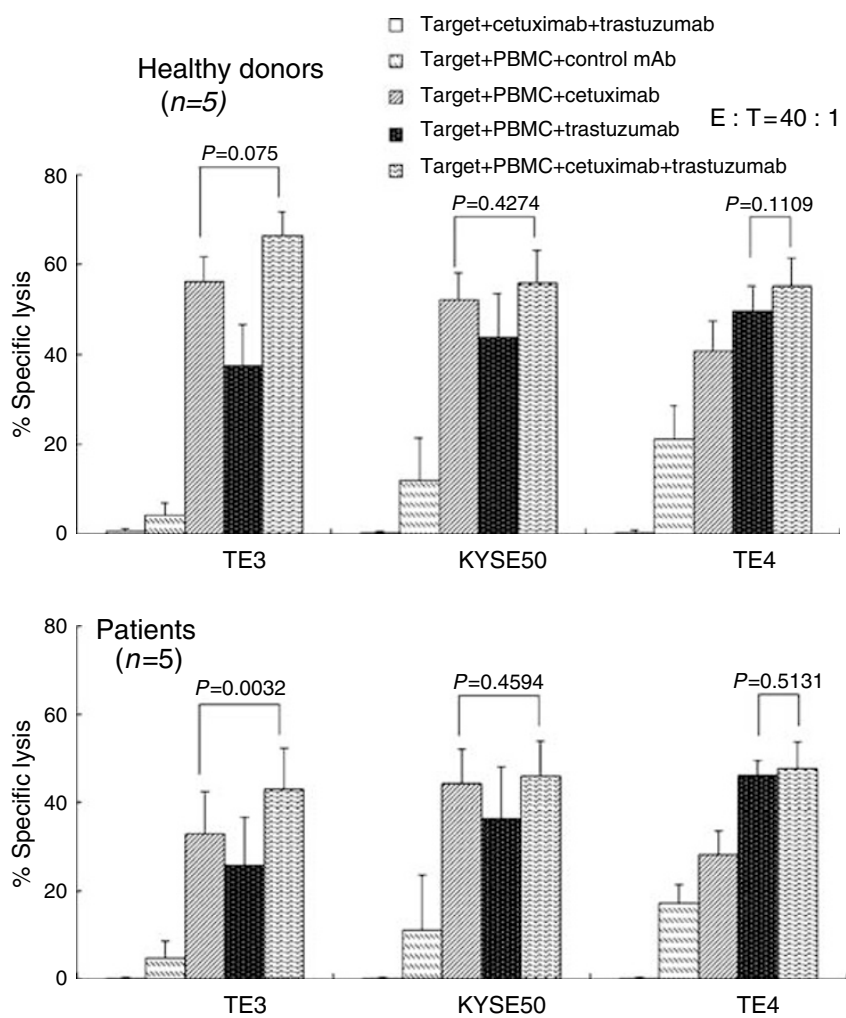

Figure 7 Cetuximab- and/or trastuzumab-mediated ADCC for oesophageal SCC in healthy donors and oesophageal SCC patients. Oesophageal SCC cell lines with various levels of EGFR and HER-2 expression were analysed for ADCC by healthy donors' PBMC and patients' PBMC in the presence of cetuximab $\left(0.5 \mu \mathrm{g} \mathrm{ml}^{-1}\right)$ and/or trastuzumab $\left(\left.10 \mu \mathrm{gml}\right|^{-1}\right)$ or control $\mathrm{mAb}\left(\left.1 \mu \mathrm{gml}\right|^{-1}\right)$ by the $6-{ }^{51} \mathrm{Cr}$ release assay. Summarised data from healthy donors' PBMC $(n=5)$ and oesophageal cancer patients' PBMC $(n=5)$ are shown. E:T, effector/target ratios.

oesophageal SCC varying between 0 and 31\% (Sunpaweravong et al, 2005), in which the different rate of HER-2 expression seems to be due to the different criteria for evaluating the results. Importantly, both EGFR- and HER-2-positive tumours were observed in $18 \%$ of all patients, out of which $75 \%$ showed EGFR and HER-2 expression in individually distinct regions. These in vivo data suggest that combined targeting with EGFR and HER-2 may result in an additional clinical response in patients with both EGFR and HER-2 expression.

Both antibodies were reported to have functions including internalisation and downregulation of the receptors (Fan et al, 1994; Goldstein et al, 1995; Sliwkowski et al, 1999), inhibition of tyrosine kinase activity (Sato et al, 1983), inhibition of cell cycle progression (Wu et al, 1995; Peng et al, 1996), and increased levels and activities of pro-apoptotic molecules (Wu et al, 1995; Liu et al, 2001). In addition, we recently reported that trastuzumab could induce ADCC activity for oesophageal SCC (Mimura et al, 2005a) or gastric cancer (Kono et al, 2002).

It has been shown that treatment with cetuximab or trastuzumab for breast cancer cells promoted the specific induction of pro-apoptotic molecules and resulted in the upregulation of chemosensitisation (Real et al, 2005). Furthermore, it has been reported that EGFR-HER-2 heterodimers are rate-limiting in the EGF-mediated proliferation of tumour cells (Hsieh et al, 2000). These results suggested that EGFR and HER-2 may interact with each other and lead to effective antitumour activity. As a novel and important finding in the present study, the combination of cetuximab and trastuzumab could induce synergistic antiproliferative effects against several oesophageal SCC cell lines with 
EGFR and HER-2 expression. However, the levels of EGFR and HER-2 expression in oesophageal SCC cell lines was not the only factor predicting the sensitivity to cetuximab and trastuzumab, since SCC cell lines, such as KYSE50 and TE5, with almost the same level of EGFR and HER-2 - expression, had a different amount of synergistic, antiproliferative effects with cetuximab and trastuzumab. Further investigation is necessary to elucidate the factors that affect the antitumour effect of cetuximab and trastuzumab combination.

In conclusion, the combination of cetuximab and trastuzumab could induce synergistic antiproliferative effects and additional

\section{REFERENCES}

Abd El-Rehim DM, Pinder SE, Paish CE, Bell JA, Rampaul RS, Blamey RW, Robertson JF, Nicholson RI, Ellis IO (2004) Expression and coexpression of the members of the epidermal growth factor receptor (EGFR) family in invasive breast carcinoma. Br J Cancer 91: 1532-1542

Akiyama H, Tsurumaru M, Udagawa H, Kajiyama Y (1994) Radical lymph node dissection for cancer of the thoracic esophagus. Ann Surg 220: $364-373$

Ando N, Iizuka T, Ide H, Ishida K, Shinoda M, Nishimaki T, Takiyama W, Watanabe $\mathrm{H}$, Isono $\mathrm{K}$, Aoyama $\mathrm{N}$, Makuuchi $\mathrm{H}$, Tanaka $\mathrm{O}$, Yamana $\mathrm{H}$, Ikeuchi S, Kabuto T, Nagai K, Shimada Y, Kinjo Y, Fukuda H (2003) Surgery plus chemotherapy compared with surgery alone for localized squamous cell carcinoma of the thoracic esophagus: a Japan Clinical Oncology Group Study - JCOG9204. J Clin Oncol 21: 4592-4596

Ando N, Ozawa S, Kitagawa Y, Shinozawa Y, Kitajima M (2000) Improvement in the results of surgical treatment of advanced squamous esophageal carcinoma during 15 consecutive years. Ann Surg 232: 225-232

Chow NH, Chan SH, Tzai TS, Ho CL, Liu HS (2001) Expression profiles of ErbB family receptors and prognosis in primary transitional cell carcinoma of the urinary bladder. Clin Cancer Res 7: 1957-1962

Cuello M, Ettenberg SA, Clark AS, Keane MM, Posner RH, Nau MM, Dennis PA, Lipkowitz S (2001) Down-regulation of the erbB-2 receptor by trastuzumab (herceptin) enhances tumor necrosis factor-related apoptosis-inducing ligand-mediated apoptosis in breast and ovarian cancer cell lines that overexpress erbB-2. Cancer Res 61: 4892-4900

Di Lorenzo G, Tortora G, D'Armiento FP, De Rosa G, Staibano S, Autorino R, D’Armiento M, De Laurentiis M, De Placido S, Catalano G, Bianco AR, Ciardiello F (2002) Expression of epidermal growth factor receptor correlates with disease relapse and progression to androgen-independence in human prostate cancer. Clin Cancer Res 8: 3438-3444

DiGiovanna MP, Stern DF, Edgerton SM, Whalen SG, Moore II D, Thor AD (2005) Relationship of epidermal growth factor receptor expression to ErbB-2 signaling activity and prognosis in breast cancer patients. J Clin Oncol 23: $1152-1160$

Dragovich T, McCoy S, Fenoglio-Preiser CM, Wang J, Benedetti JK, Baker AF, Hackett CB, Urba SG, Zaner KS, Blanke CD (2006) Phase II trial of erlotinib in gastroesophageal junction and gastric adenocarcinoma: SWOG 0127. J Clin Oncol 24: 4922-4927

Fan Z, Lu Y, Wu X, Mendelsohn J (1994) Antibody-induced epidermal growth factor receptor dimerization mediates inhibition of autocrine proliferation of A431 squamous carcinoma cells. J Biol Chem 269: 27595-27602

Fukuoka M, Yano S, Giaccone G, Tamura T, Nakagawa K, Douillard JY, Nishiwaki Y, Vansteenkiste J, Kudoh S, Rischin D, Eek R, Horai T, Noda K, Takata I, Smit E, Averbuch S, Macleod A, Feyereislova A, Dong RP, Baselga J (2003) Multi-institutional randomized phase II trial of gefitinib for previously treated patients with advanced non-small-cell lung cancer (The IDEAL 1 Trial). J Clin Oncol 21: 2237-2246

Ghaderi A, Vasei M, Maleck-Hosseini SA, Gharesi-Fard B, Khodami M, Doroudchi M, Modjtahedi H (2002) The expression of c-erbB-1 and c-erbB-2 in Iranian patients with gastric carcinoma. Pathol Oncol Res 8: $252-256$

Goldstein NI, Prewett M, Zuklys K, Rockwell P, Mendelsohn J (1995) Biological efficacy of a chimeric antibody to the epidermal growth factor receptor in a human tumor xenograft model. Clin Cancer Res 1: 1311-1318

Graus-Porta D, Beerli RR, Daly JM, Hynes NE (1997) ErbB-2, the preferred heterodimerization partner of all ErbB receptors, is a mediator of lateral signaling. EMBO J 16: $1647-1655$
ADCC activities against several oesophageal SCC cells. A better understanding of the detailed mechanisms involved in EGFR and/ or HER-2 may help identify new therapeutic targets in oesophageal SCC.

\section{ACKNOWLEDGEMENTS}

This work was supported by a grant from the Ministry of Education, Culture, Sports, Science and Technology of Japan.
Hanawa M, Suzuki S, Dobashi Y, Yamane T, Kono K, Enomoto N, Ooi A (2006) EGFR protein overexpression and gene amplification in squamous cell carcinomas of the esophagus. Int J Cancer 118: 1173-1180

Hayashi Y, Widjono YW, Ohta K, Hanioka K, Obayashi C, Itoh K, Imai Y, Itoh H (1994) Expression of EGF, EGF-receptor, p53, v-erb B and ras p21 in colorectal neoplasms by immunostaining paraffin-embedded tissues. Pathol Int 44: 124-130

Herbst RS, Hong WK (2002) IMC-C225, an anti-epidermal growth factor receptor monoclonal antibody for treatment of head and neck cancer. Semin Oncol 29: 18-30

Hirsch FR, Scagliotti GV, Langer CJ, Varella-Garcia M, Franklin WA (2003) Epidermal growth factor family of receptors in preneoplasia and lung cancer: perspectives for targeted therapies. Lung Cancer 41(Suppl 1): S29-S42

Hsieh SS, Malerczyk C, Aigner A, Czubayko F (2000) ERbB-2 expression is rate-limiting for epidermal growth factor-mediated stimulation of ovarian cancer cell proliferation. Int J Cancer 86: 644-651

Ishikura S, Nihei K, Ohtsu A, Boku N, Hironaka S, Mera K, Muto M, Ogino T, Yoshida S (2003) Long-term toxicity after definitive chemoradiotherapy for squamous cell carcinoma of the thoracic esophagus. J Clin Oncol 21: 2697-2702

Itakura Y, Sasano H, Shiga C, Furukawa Y, Shiga K, Mori S, Nagura H (1994) Epidermal growth factor receptor overexpression in esophageal carcinoma. An immunohistochemical study correlated with clinicopathologic findings and DNA amplification. Cancer 74: 795-804

Kimura M, Tsuda H, Morita D, Ichikura T, Ogata S, Aida S, Yoshizumi Y, Maehara T, Mochizuki H, Matsubara O (2004) A proposal for diagnostically meaningful criteria to classify increased epidermal growth factor receptor and c-erbB-2 gene copy numbers in gastric carcinoma, based on correlation of fluorescence in situ hybridization and immunohistochemical measurements. Virchows Arch 445: 255-262

Kono K, Takahashi A, Ichihara F, Sugai H, Fujii H, Matsumoto Y (2002) Impaired antibody-dependent cellular cytotoxicity mediated by herceptin in patients with gastric cancer. Cancer Res 62: 5813-5817

Kwak EL, Jankowski J, Thayer SP, Lauwers GY, Brannigan BW, Harris PL, Okimoto RA, Haserlat SM, Driscoll DR, Ferry D, Muir B, Settleman J, Fuchs CS, Kulke MH, Ryan DP, Clark JW, Sgroi DC, Haber DA, Bell DW (2006) Epidermal growth factor receptor kinase domain mutations in esophageal and pancreatic adenocarcinomas. Clin Cancer Res 12: $4283-4287$

Liu B, Fang M, Lu Y, Mendelsohn J, Fan Z (2001) Fibroblast growth factor and insulin-like growth factor differentially modulate the apoptosis and G1 arrest induced by anti-epidermal growth factor receptor monoclonal antibody. Oncogene 20: 1913-1922

Mendelsohn J, Baselga J (2003) Status of epidermal growth factor receptor antagonists in the biology and treatment of cancer. J Clin Oncol 21: $2787-2799$

Mimura K, Kono K, Hanawa M, Kanzaki M, Nakao A, Ooi A, Fujii H (2005a) Trastuzumab-mediated antibody-dependent cellular cytotoxicity against esophageal squamous cell carcinoma. Clin Cancer Res 11: $4898-4904$

Mimura K, Kono K, Hanawa M, Mitsui F, Sugai H, Miyagawa N, Ooi A, Fujii H (2005b) Frequencies of HER-2/neu expression and gene amplification in patients with oesophageal squamous cell carcinoma. Br J Cancer 92: $1253-1260$

Needle MN (2002) Safety experience with IMC-C225, an anti-epidermal growth factor receptor antibody. Semin Oncol 29: 55-60 
Ooi A, Takehana T, Li X, Suzuki S, Kunitomo K, Iino H, Fujii H, Takeda Y, Dobashi Y (2004) Protein overexpression and gene amplification of HER-2 and EGFR in colorectal cancers: an immunohistochemical and fluorescent in situ hybridization study. Mod Pathol 17: 895-904

Ozawa S, Ueda M, Ando N, Shimizu N, Abe O (1989) Prognostic significance of epidermal growth factor receptor in esophageal squamous cell carcinomas. Cancer 63: 2169-2173

Peng D, Fan Z, Lu Y, DeBlasio T, Scher H, Mendelsohn J (1996) Antiepidermal growth factor receptor monoclonal antibody 225 up-regulates p27KIP1 and induces G1 arrest in prostatic cancer cell line DU145. Cancer Res 56: 3666-3669

Pisani P, Parkin DM, Ferlay J (1993) Estimates of the worldwide mortality from eighteen major cancers in 1985. Implications for prevention and projections of future burden. Int J Cancer 55: 891 - 903

Porebska I, Harlozinska A, Bojarowski T (2000) Expression of the tyrosine kinase activity growth factor receptors (EGFR, ERB B2, ERB B3) in colorectal adenocarcinomas and adenomas. Tumour Biol 21: 105-115

Ranson M, Mansoor W, Jayson G (2002) ZD1839 (IRESSA): a selective EGFR-TK inhibitor. Expert Rev Anticancer Ther 2: 161-168

Real PJ, Benito A, Cuevas J, Berciano MT, de Juan A, Coffer P, GomezRoman J, Lafarga M, Lopez-Vega JM, Fernandez-Luna JL (2005) Blockade of epidermal growth factor receptors chemosensitizes breast cancer cells through up-regulation of Bnip3L. Cancer Res 65: 8151-8157

Sato JD, Kawamoto T, Le AD, Mendelsohn J, Polikoff J, Sato GH (1983) Biological effects in vitro of monoclonal antibodies to human epidermal growth factor receptors. Mol Biol Med 1: 511-529

Sliwkowski MX, Lofgren JA, Lewis GD, Hotaling TE, Fendly BM, Fox JA (1999) Nonclinical studies addressing the mechanism of action of trastuzumab (Herceptin). Semin Oncol 26: 60-70

Sunpaweravong P, Sunpaweravong S, Puttawibul P, Mitarnum W, Zeng C, Garcia MV (2005) Epidermal growth factor receptor and cyclin D1 are independently amplified and overexpressed in esophageal squamous cell carcinoma. J Cancer Res Clin Oncol 131: 111-119
Suo Z, Risberg B, Kalsson MG, Willman K, Tierens A, Skovlund E, Nesland JM (2002) EGFR family expression in breast carcinomas. c-erbB-2 and c-erbB-4 receptors have different effects on survival. J Pathol 196: 17-25

Takehana T, Kunitomo K, Kono K, Kitahara F, Iizuka H, Matsumoto Y, Fujino MA, Ooi A (2002) Status of c-erbB-2 in gastric adenocarcinoma: a comparative study of immunohistochemistry, fluorescence in situ hybridization and enzyme-linked immuno-sorbent assay. Int J Cancer 98: $833-837$

Tzahar E, Waterman H, Chen X, Levkowitz G, Karunagaran D, Lavi S, Ratzkin BJ, Yarden Y (1996) A hierarchical network of interreceptor interactions determines signal transduction by Neu differentiation factor/neuregulin and epidermal growth factor. Mol Cell Biol 16: $5276-5287$

Wester K, Sjostrom A, de la Torre M, Carlsson J, Malmstrom PU (2002) HER-2 - a possible target for therapy of metastatic urinary bladder carcinoma. Acta Oncol 41: 282-288

Wild R, Fager K, Flefleh C, Kan D, Inigo I, Castaneda S, Luo FR, Camuso A, McGlinchey K, Rose WC (2006) Cetuximab preclinical antitumor activity (monotherapy and combination based) is not predicted by relative total or activated epidermal growth factor receptor tumor expression levels. Mol Cancer Ther 5: 104-113

Witton CJ, Reeves JR, Going JJ, Cooke TG, Bartlett JM (2003) Expression of the HER $1-4$ family of receptor tyrosine kinases in breast cancer. J Pathol 200: $290-297$

Wu X, Fan Z, Masui H, Rosen N, Mendelsohn J (1995) Apoptosis induced by an anti-epidermal growth factor receptor monoclonal antibody in a human colorectal carcinoma cell line and its delay by insulin. J Clin Invest 95: $1897-1905$

Yano H, Shiozaki H, Kobayashi K, Yano T, Tahara H, Tamura S, Mori T (1991) Immunohistologic detection of the epidermal growth factor receptor in human esophageal squamous cell carcinoma. Cancer 67: $91-98$

Yarden Y, Sliwkowski MX (2001) Untangling the ErbB signalling network. Nat Rev Mol Cell Biol 2: 127-137 